\title{
Penile Epidermoid Cysts: A Rare Location
}

\author{
Parveen Kumar $^{1 *}$, Vivek Viswanathan ${ }^{1}$ and Arti Khatri ${ }^{2}$ \\ ${ }^{1}$ Department of Pediatric Surgery, Chacha Nehru Bal Chikitsalya, New Delhi, India \\ ${ }^{2}$ Department of Pathology, Chacha Nehru Bal Chikitsalya, New Delhi, India
}

*Corresponding author: Parveen Kumar, Department of Pediatric Surgery, Chacha Nehru Bal Chikitsalya, New Delhi, India

\begin{abstract}
Epidermoid cysts results due to implantation of epidermis tissue in dermis or subcutaneous tissue. It may be congenital or iatrogenic. We present here two rare sites with rare presentation. The meticulous surgical excision is curative.

Keywords: Epidermoid cysts; Glans epidermoid; Hypospadias
\end{abstract}

\section{Case 1}

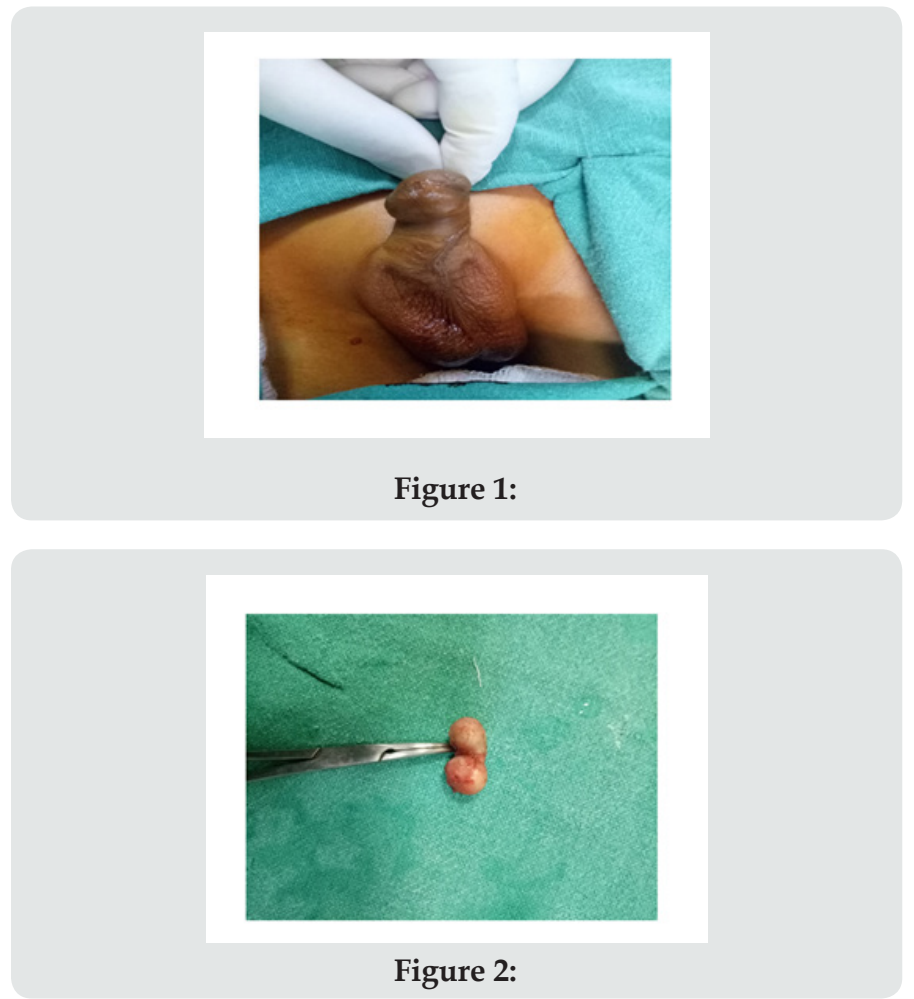

A 12-year-old boy follow up case of sub-coronal hypospadias, operated at one year of age with Snodgrass urethroplasty, presented with small penile swellings for last one year. On examination, penis was normal with neo-meatus at glans and passing urine in single good stream and evidence of two small swellings less than $1 \mathrm{~cm}$ size on ventral and right lateral shaft which were non tender, nonfluctuant and slightly mobile (Figure 1). Under mask ventilation, two epidermoid cysts were excised (Figure 2) and histopathology was consistent.

\section{Case 2}

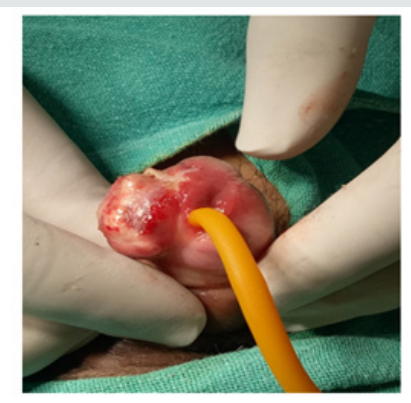

Figure 3: .

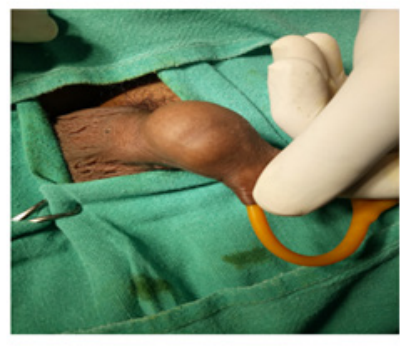

Figure 4: . 
A 13-year-old boy presented with a large swelling over glans and dorsal penile shaft for 2 years (Figures $3 \& 4$ ). It was excised and sent for histopathological examination, which revealed it to be epidermoid cyst.

\section{Discussion}

The epidermoid cyst per se may occur anywhere in human body but primary epidermoid cyst of penis is a rare occurrence. The usual location of epidermoid cyst is in the midline or the sites of bony fusion. They may occur secondary to inclusion of epidermis at the sites of bony or iatrogenic closure, so also called epidermoid inclusion cysts. It occurs secondary to proliferation of trapped or sequestered epidermal tissue, causing subcutaneous firm and mobile swellings. The penile epidermoid cysts are usually reported in older age group. The literature reports that median raphe cysts are result of faulty embryological development in males [1]. Both of our cases had cysts away from median raphe, raising possibility of idiopathic cause. It is very difficult to label epidermoid cyst in case 1 as primary or secondary as though it was post urethroplasty, it appeared 10 years after surgery and also was away from neourethra. The idiopathic form of penile epidermoid cyst is also reported in literature in a young child [1].

The physical examination is all that is needed for diagnosis. Rarely, radiological assessment with ultrasound may be sought.
The differential diagnosis may include steatocystomas or rarely teratoma. Khanna S reported first case of glans epidermoid from India in 1991 [2]. The meticulous surgical excision is treatment of choice. Care should be taken to avoid rupture of capsule of cyst to avoid recurrence. Histologic examination confirms the diagnosis, with cyst showing keratinized stratified squamous epithelium containing sebaceous or pultaceous material. Erikci VS et al reported first case of epidermoid cyst in an operated case of hypospadias at the age of 5 years (after 4 years of surgery) [3]. Our case 1 is probably the second case such reported and first with such late presentation post hypospadias surgery (after 10 years) and without any other complications.

\section{Conclusion}

Care should be taken at the time of surgical interventions on phallus, to avoid implantation of epidermis, to avoid possible future epidermoid cyst.

\section{References}

1. Aslan Y, Balci M, Atan A (2011) Idiopathic penile epidermoid cyst in a young patient: three year follow up. Eur J Surg Sci 2(1): 16-18.

2. Khanna S (1991) Epidermoid cyst of the glans penis. European urology 19: 176-177.

3. Erikci VS, Öney MD Köylüoğlu G (2017) A Rare Complication after Urethroplasty: Epidermoid Inclusion Cyst. SM J Pediatr Surg 3(2): 1045.
This work is licensed under Creative Commons Attribution 4.0 License

To Submit Your Article Click Here: $\quad$ Submit Article

DOI: $10.32474 /$ SCSOAJ.2019.03.000164

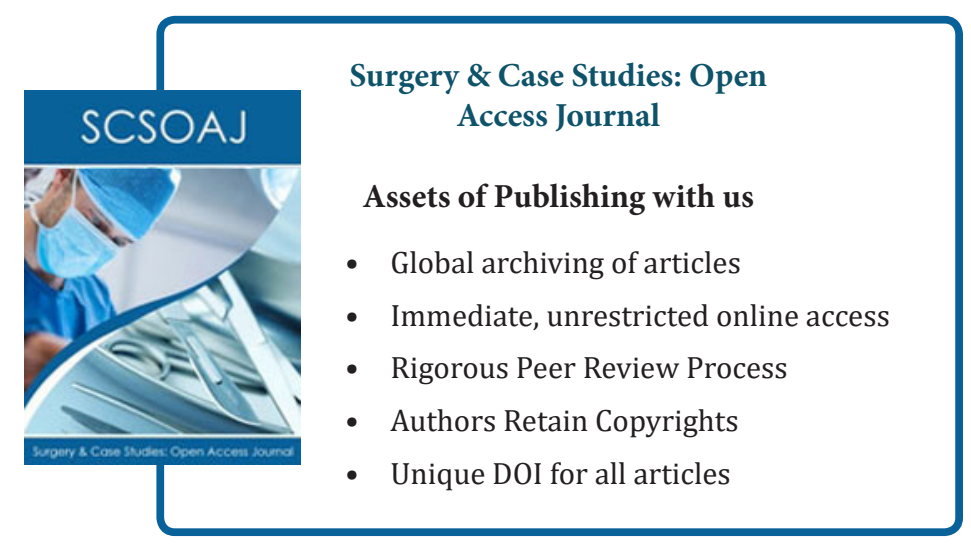

